\title{
SOBRE A MANIFESTAÇÃO MORFOLÓGICA DE GÊNERO: ABORDAGENS FORMAIS E PSICOLINGUÍSTICAS*
}

Cristina Name**

(iD) https://orcid.org/0000-0001-5625-9503

Paula Roberta Gabbai Armelin $* * *$

(iD) https://orcid.org/0000-0003-4751-2831

Mercedes Marcilese ${ }^{\star * \star *}$

(iD) https://orcid.org/0000-0002-9058-8367

Como citar este artigo: NAME, C.; ARMELIN, P. R. G.; MARCILESE, M. Sobre a manifestação morfológica de gênero: abordagens formais e psicolinguísticas. Todas as Letras - Revista de Língua e Literatura, São Paulo, v. 22, n. 1, p. 1-18, jan./abr. 2020. DOI 10.5935/1980-6914/eLETDO2012845

Submissão: setembro de 2019. Aceite: fevereiro de 2020.

Resumo: Este trabalho revisita, de forma panorâmica, questões relativas à noção de gênero gramatical a partir de perspectivas linguisticas e psicolinguísticas. De maneira geral, são exploradas três grandes questões: 1. o lugar da informação de gênero; 2. a relação entre o valor do gênero e a terminação do nome; e 3. as relações de concordância estabelecidas entre nome, adjetivo e determinante. Aspectos de cada uma dessas questões são explorados em um viés formalista, a partir de evidências do processamento adulto e da perspectiva da aquisição da linguagem.

Palavras-chave: Morfossintaxe. Gênero gramatical. Formalismo. Processamento da linguagem. Aquisição da linguagem.

O projeto de pesquisa ao qual o presente artigo se vincula teve apoio da Fundação de Amparo à Pesquisa do Estado de Minas Gerais (Fapemig) (Processo n. APQ-00988/15) e conta com a aprovação do Comitê de Ética em Pesquisa/UFJF (CAAE: 44123015. 6.0000.5147).

** Universidade Federal de Juiz de Fora (UFJF), Juiz de Fora, MG, Brasil. Bolsista de Produtividade de Pesquisa do CNPq. E-mail: cristina.name@ufjf.edu.br.

*** Universidade Federal de Juiz de Fora (UFJF), Juiz de Fora, MG, Brasil. E-mail: paula.rg.armelin@gmail.com

$* * * *$ Universidade Federal de Juiz de Fora (UFJF), Juiz de Fora, MG, Brasil. E-mail: mmarcilese@gmail.com 


\section{INTRODUÇÃo}

D istinções gramaticais baseadas em informação de gênero são bastante frequentes nas línguas naturais. Embora a literatura careça de dados precisos $^{1}$, estima-se que $75 \%$ das linguas do mundo apresentem sistema de gênero gramatical (MALLINSON; BLAKE, 1981 apud VAN BERKUM, 1997). De modo geral, no que diz respeito às línguas que estabelecem distinções relacionadas a gênero, são observados, de um lado, correlatos morfofonológicos com algum grau de padronização para os diferentes valores do traço de gênero nos elementos do Nome $(\mathrm{N})$ - vogal final (por exemplo, em português e espanhol) e/ou terminação (em francês e também em português); e, de outro lado, relações de concordância de gênero entre $\mathrm{N}$ e elementos das categorias Determinante (D) e Adjetivo (ADJ) ${ }^{2}$, com manifestação morfofonológica nesses elementos.

A manifestação da informação de gênero gramatical - em termos de sua identificação, representação e computação - tem se mostrado um fenômeno de interesse para as abordagens linguísticas e psicolinguísticas, especialmente por se colocar na interface entre diversos niveis, tais como o léxico, a sintaxe, a semântica e a morfologia, por exemplo. Dessa maneira, a compreensão da codificação e do funcionamento da informação de gênero tem o potencial de contribuir amplamente para a construção de um modelo adequado de gramática, tanto no âmbito de teorias formais quanto de modelos de processamento.

Exatamente por se caracterizar naturalmente como um fenômeno de interface, o gênero se destaca como um elemento de acentuado debate na literatura ou, como aponta Matasović (2004, p. 13), "gender is perhaps the only grammatical category that ever evoked passion" . Desse modo, trata-se de um tema que está cercado de muitas controvérsias, tendo se consagrado, portanto, como "the most puzzling of the grammatical categories" ${ }^{4}$ nas palavras de Corbett $(1991, \mathrm{p} .1)$.

No presente artigo, abordamos a questão do gênero a partir de três perspectivas distintas, mas, ao mesmo tempo, em boa medida complementares. Em primeiro lugar, a noção de gênero é discutida no que diz respeito à sua abordagem no contexto de teorias de cunho formalista. Em seguida, apresentamos alguns pontos centrais investigados na perspectiva do processamento linguístico por falantes adultos no que tange à representação, acesso e computação das informações de gênero gramatical. Ainda no que tange à dimensão processual, abordamos a questão da informação de gênero na aquisição da linguagem, em particular, quanto à identificação de tais informações no input recebido pela criança.

Consideradas em conjunto, as perspectivas aqui levantadas estão ligadas por colocarem em discussão aspectos relacionados a três grandes questões:

\footnotetext{
1 De acordo com o World Atlas of Language Structures Online, considerando-se um universo de 257 línguas já estudadas, por volta de $43 \%$ (i. e., 112 delas) apresentariam algum sistema de gênero gramatical (CORBETT, 2013). Observam-se, no entanto, a ausência de línguas como o português, o holandês e o sueco, tratadas pelo mesmo autor em obra anterior (CORBETT, 1991), e poucas línguas africanas contabilizadas. Segundo Heine (1982 apud CORBETT, 1991), dois terços das línguas faladas no continente africano (cerca de 600) manifestariam relações de concordância de gênero.

2 Conforme apontam Corbett (1991), Van Berkum (1997) e Comrie (1999), entre outros, há línguas com sistemas de gênero apresentando relações de concordância também com elementos de outras categorias, como V. No entanto, observa-se com mais frequência a concordância com adjetivos e determinantes, sobretudo com esses últimos, como ressalta Name (2002, p. 42).

3 "Talvez o gênero seja a única categoria gramatical que já evocou paixão" (tradução nossa).

4 "A mais intrigante das categorias gramaticais" (tradução nossa).
} 
(a) o lugar da informação de gênero;

(b) a relação entre a informação de gênero e a realização morfofonológica final do nome;

(c) as relações de concordância estabelecidas dentro do sintagma determinante.

Certamente, tais questões não esgotam as controvérsias ligadas à noção de gênero, mas a escolha por elas se justifica na medida em que são representativas do seu caráter de interface, ao mesmo tempo em que se relacionam a questões exploradas nas perspectivas de viés psicolinguístico, tanto no que diz respeito ao processamento adulto como na aquisição da linguagem, que também são exploradas neste trabalho.

Para finalizar, levantamos algumas considerações gerais com o intuito de abrir possiveis caminhos para futuras pesquisas que visem a articular modelos formais e de processamento para uma melhor compreensão do fenômeno em discussão.

\section{GÊNERO NAS ABORDAGENS FORMALISTAS}

Nesta seção, apresentamos algumas das propostas disponiveis na literatura formalista para discutir a noção de gênero. Mais especificamente, limitamo-nos a propostas desenvolvidas sob um enfoque gerativista e delineamos o debate exatamente a partir das três grandes questões de (a) a (c) anunciadas na seção de introdução e que, de maneira geral, norteiam o recorte proposto ao longo deste artigo.

\section{O LUGAR Do TRAÇO DE GÊNERO}

Na perspectiva teórica do Programa Minimalista, Chomsky $(2000,2001)$ propõe que os Ns entram na derivação sintática com seu traço de gênero especificado, sendo que tal especificação é determinada no próprio léxico. Chomsky (2001) propõe ainda que também a interpretabilidade dos traços morfossintáticos é determinada no léxico. Dessa maneira, os traços interpretáveis entram na derivação com seu valor já especificado, enquanto os traços não interpretáveis adquirem seu valor via concordância. Enquanto a mecânica do sistema de concordância será um tema abordado mais adiante, interessa-nos, nesse ponto do texto, a ideia de que o gênero é compreendido como um dos primitivos que integra, inerentemente, a composição de $\mathrm{N}$.

Outros trabalhos, anteriores e posteriores ao sistema de Chomsky, têm se dedicado a estabelecer exatamente em que lugar da estrutura de $\mathrm{N}$ o traço de gênero está codificado. Essas abordagens tipicamente incluem uma decomposição mais articulada das projeções funcionais que constituem a estrutura interna de N. A partir de dados do catalão, por exemplo, Picallo (1991) propõe a existência de um núcleo funcional de gênero que imediatamente domina a projeção máxima de $\mathrm{N}$ e que é dominado por uma projeção de número. O núcleo lexical de $\mathrm{N}$ se moveria sucessivamente para os núcleos funcionais acima dele, gerando a seguinte ordenação: base-gênero-número.

A existência, no entanto, de uma projeção exclusivamente relacionada a gênero na projeção estendida de $\mathrm{N}$ não é consenso na literatura que explora a estrutura interna dos nomes. Dentre outras razões, a interpretabilidade dessa projeção tem sido alvo de questionamento, em especial quando o gênero pura- 
mente gramatical e arbitrário é levado em consideração. Nesse sentido, o questionamento se dá com base na inadequação de uma projeção sintática que contenha somente traços não interpretáveis.

Por sua vez, Ritter (1993) argumenta contra uma projeção sintática de gênero e desenvolve uma proposta em que gênero é entendido ora como traço do núcleo lexical $\mathrm{N}$, ora como traço da projeção de número, a depender da língua em questão. Em línguas como o hebraico, em que o gênero é derivacional, trata-se de uma informação em $\mathrm{N}$ adicionada morfologicamente no léxico. Por outro lado, nas línguas românicas, em que o gênero é flexional, trata-se de uma informação que integra a projeção de número. A argumentação da autora se dá a partir de dados do romeno - em que há uma interação entre o plural dos nomes e uma alteração dos traços de gênero - e do valão - em que há uma única peça morfofonológica indicando, ao mesmo tempo, gênero e número. Esse tipo de argumentação, no entanto, não parece consistente com todas as linguas românicas. No PB, por exemplo, a marca de plural é dissociada de gênero e não há alteração do gênero do nome quando se comparam as formas plural e singular de um mesmo elemento.

No âmbito especificamente da Morfologia Distribuída (HALLE; MARANTZ, 1993 e diversos trabalhos subsequentes), doravante MD, em que uma decomposição ainda mais articulada da estrutura interna de $\mathrm{N}$ tem sido proposta, duas possibilidades de codificação do gênero são encontradas na literatura: 1. gênero codificado na própria raiz (EMBICK, 2015); e 2. gênero codificado no categorizador nominal (KIHM, 2005; LOWENSTAMM, 2008; ACQUAVIVA, 2009; KRAMER, 2015).

Do ponto de vista teórico, no entanto, para um modelo de análise que trabalha com a acategorialidade das raizes, tal como a MD, abordagens que equipam a raiz com traços de gênero não parecem uma saída interessante. Conforme apontado em Acquaviva (2009), tal informação acaba por ser uma espécie de dica a respeito de qual categoria a raiz em questão pode assumir. Se assim for, o estatuto acategorial da raiz acaba por ser consideravelmente enfraquecido, resultando em um modelo mais lexical do que sintático para a formação de palavras. Do ponto de vista empírico, também não são raros os casos em que uma mesma raiz pode se superficializar em contextos com diferentes valores para o traço de gênero, de modo que tal informação não parece, portanto, ser de fato uma propriedade inerente à raiz.

Diante dessas questões, diversas abordagens no âmbito da MD têm proposto que o gênero é um traço, não da raiz, mas de uma projeção funcional que é responsável pela definição da categoria nominal, mais especificamente o núcleo $n$. Um dos argumentos que sustentam essa hipótese é a interação de categorizadores nominais fonologicamente realizados que determinam o gênero da formação, tais como - al e -ção no PB, que, respectivamente, formam substantivos masculinos, como em laranjal, e femininos, como plantação. Além disso, as lacunas detectadas na associação de determinadas raízes a determinados valores de gênero poderiam ser explicadas por uma relação de localidade entre a raiz e seu categorizador.

\section{A REALIZAÇÃo MORFOFONOLÓGICA DA INFORMAÇÃo DE GÊNERO}

No que diz respeito à realização morfofonológica da informação de gênero em $\mathrm{N}$, é preciso levar em conta a tradicional distinção entre gênero e classe nominal. 
De modo geral, as diferentes classes nominais são determinadas a partir da terminação fonológica que o nome apresenta. Em PB, essa terminação fonológica é representada pelas vogais átonas $-a,-o,-e$, ou por um $\varnothing$ fonológico. É possivel encontrar generalizações na relação entre gênero e classe: a maioria dos nomes terminados em - $a$ tende a ser feminino, enquanto a maioria dos nomes terminados em -o tende a ser masculino ${ }^{5}$. No entanto, as marcas de gênero e classe não coincidem sempre e, por esse motivo, não é possivel prever a classe nominal com base nas informações de gênero ou vice-versa. Nesse sentido, há nomes masculinos e femininos em todas as classes flexionais. Diante disso, emerge como questão qual é exatamente o limite entre as noções de classe e de gênero.

Segundo Câmara Jr. (1970), a única marcação de gênero no PB é a vogal final - a em pares como gato/gata, mestre/mestra e peru/perua, por exemplo. Dada a variação na vogal final da forma masculina $(-o,-e, \varnothing$, respectivamente), o autor sugere que o gênero masculino é realizado através de um morfema zero. Consequentemente, Câmara Jr. (1970) assume uma assimetria entre as vogais finais - $a$ e - o. De fato, o estatuto formal dessas vogais finais foi investigado em diferentes linguas românicas e sob uma variedade de perspectivas teóricas. Tais abordagens apresentam muitas diferenças, mas, de maneira bastante geral, podemos dividi-las em dois tipos: 1 . análises que preveem um estatuto diferente para as vogais - $a$ e -o (CÂMARA JR., 1970, por exemplo); e 2. análises que propõem um status semelhante de - $a$ e -o (OLTRA-MASSUET, 1999; ALCÂNTARA, 2010; ARMELIN, 2014).

Mesmo no que diz respeito às abordagens inseridas na corrente mencionada em 2., há controvérsias bastante interessantes no que diz respeito à análise formal dessas vogais. Para alguns autores (OLTRA-MASSUET, 1999; ALCÂNTARA, 2010, por exemplo), tais vogais são marcadores de classe nominal. Nessa perspectiva, a vogal temática é um elemento ausente na sintaxe, mas posteriormente adicionado na morfologia para satisfazer um requerimento de boa formação. Tal perspectiva tem sido trabalhada, por exemplo, com base no modelo teórico da MD em que a adição dos chamados morfemas dissociados no componente morfológico é uma operação possível. Um problema para essa abordagem, já apontado em Alexiadou e Müller (2008), é que a inserção pós-sintática de um nó terminal está em desacordo com a Condição de Inclusividade (CHOMSKY, 1995), que proíbe que o output da derivação contenha elementos a mais do que aqueles presentes em seu input. Nesse contexto, faz-se ainda necessário notar que o conceito do que uma "condição de boa formação morfológica", responsável pela inserção do nó que carrega a vogal temática, realmente significa não é muito claro e, assim sendo, acaba por se tornar um recurso de análise mais descritivo do que realmente explicativo. Finalmente, dispensar a vogal temática de qualquer relação com o significado final da formação acaba por complicar a explicação de dados, tais como barco-barca ou mato-mata, em que uma alteração na vogal corresponde também a uma espécie de alteração na interpretação. Nesse sentido, se a vogal final é irrelevante para a interpretação, então, a diferença entre os componentes desses pares fica ou a cargo da própria raiz, o que implica

5 Na seção dedicada à abordagem psicolinguística da informação de gênero retomaremos a questão dessa quase generalização da terminação dos nomes no que tange ao processamento linguístico. Taft e Meunier (1998), ao examinarem a representação lexical do gênero no francês num viés psicolinguístico, consideram que a relação entre gênero e a terminação dos nomes nessa língua pode ser definida em termos de um "domínio quase-regular". Essa observação se mostra válida para outras línguas românicas como o espanhol e o português. Esse ponto será melhor desenvolvido mais à frente. 
assumir que a raiz é provida de propriedades semânticas, ou a cargo da postulação de raízes homônimas, ambas sendo assunções problemáticas no âmbito do modelo.

Por outro lado, Armelin (2014) propõe que as marcas de gênero e de classe nominal ocupam a mesma posição na estrutura sintática. Em linhas gerais, a autora propõe que o que foi tradicionalmente separado em gênero e classe nominal represente tão somente diferentes possibilidades de realização fonológica de um mesmo núcleo sintático. O sistema resultante dispensa a necessidade de diacríticos de classe tanto na raiz quanto em qualquer dos estágios da derivação. A partir da noção de inserção tardia assumida no modelo da MD, na proposta de Armelin (2014), a fonologia resultante de um traço de gênero pode ser tanto um item default como um elemento mais especificado. Os itens default mapeiam o núcleo de gênero para - $a$ no contexto de feminino e para -o no contexto de masculino. Por outro lado, os casos em que a forma fonológica da vogal final é imprevisível são explicados como o resultado da existência de itens de vocabulário mais especificados, que incluem as raizes relevantes em sua especificação contextual.

\section{GÊNERo E O SISTEMA DE CONCORDÂNCIA}

Quando se fala em concordância na teoria gerativa, destaca-se, especificamente no âmbito do Programa Minimalista, o sistema de Agree desenvolvido em Chomsky (1995) a partir da noção de checagem e em Chomsky $(2000,2001)$ a partir da ideia de valoração ${ }^{6}$. Computacionalmente, Agree é um processo bastante geral, que se baseia nos seguintes ingredientes:

1 Distinção entre traços interpretáveis e não interpretáveis.

2. Relação apropriada entre sonda e alvo, que inclui:

(a) sonda e alvo sintaticamente ativos;

(b) c-comando entre sonda e alvo;

(c) ausência de interventor entre sonda e alvo;

(d) sonda e alvo contidos da mesma fase.

A intepretabilidade dos traços é, segundo Chomsky (2001), determinada pela própria Gramática Universal (GU), sendo que os traços não interpretáveis são aqueles que não têm seu valor especificado no léxico e que, portanto, precisam ser valorados durante a computação sintática por questões de legibilidade nas interfaces. Por sua vez, os traços interpretáveis vêm com valores especificados já no léxico é exatamente a operação de Agree que tem o potencial de transferir esses valores para um traço de natureza compativel, mas que esteja, até então, sem um valor atribuído.

Dessa maneira, o núcleo sintático que contém os traços não interpretáveis é chamado de "sonda", enquanto aquele que contém os traços interpretáveis é o "alvo". Agree, portanto, pode ser entendido como uma relação de traços estabelecida entre uma sonda que, precisando valorar seus traços, busca um alvo no seu domínio. Essa relação, no entanto, está sujeita a quatro condições impor-

6 É importante destacar que, desde Chomsky $(2000,2001)$, muitos autores já propuseram alterações de vários dos aspectos que compõem o sistema de Agree (cf. BAKER, 2008; BÉJAR; REZACK, 2009; PREMINGER, 2014, entre outros trabalhos). 
tantes. A primeira delas é que a sonda e o alvo precisam estar sintaticamente ativos, o que significa que ambos precisam conter algum traço de natureza não interpretável. A segunda condição é de natureza estrutural e diz respeito à necessidade de que haja c-comando entre a sonda e o alvo. Por fim, a terceira e a quarta condições estão relacionadas a restrições de localidade entre sonda e alvo. Mais especificamente, não pode haver um núcleo interventor a entre sonda e alvo, tal que esse núcleo a seja c-comandado pela sonda e c-comande o alvo, podendo servir, portanto, como um alvo alternativo. Por fim, sonda e alvo precisam estar contidos no mesmo domínio de fase. Satisfeitas essas condições, a operação de Agree, então, valora e deleta os traços não interpretáveis, tornando a sonda e o alvo inativos.

É interessante ressaltar, no entanto, que a intepretabilidade de um traço depende não exatamente do traço em si, mas da natureza do elemento linguístico que carrega esse traço. Especificamente, por exemplo, no que diz respeito ao traço de número e de pessoa, Chomsky $(2000,2001)$ propõe que eles sejam valorados e interpretáveis em N, mas não em T, núcleo funcional da projeção estendida do verbo, que, então, recebe os valores adequados de número e pessoa via Agree.

No entanto, nesse sistema de Chomsky, Agree não é o único tipo de operação de concordância assumida no sistema: "there is presumably a similar but distinct agreement relation, Concord, involving merge alone" (CHOMSKY, 2001, p. 42). Mais especificamente, para o autor, Agree estaria restrito ao nivel da sentença, enquanto a segunda operação atuaria no interior do sintagma, por exemplo, no interior do sintagma determinante (DP, do inglês Determiner Phrase), sendo desencadeada via Merge. Contudo, alguns autores, como Magalhães (2004), por exemplo, têm questionado a necessidade dessa separação dos processos de concordância em mecanismos distintos.

Especificamente no que diz respeito ao trabalho de Magalhães (2004), a autora desenvolve um sistema de Agree no interior do DP, basicamente adaptando o mecanismo proposto pelo próprio Chomsky (1995) para dar conta das construções participiais. Em particular no que diz respeito ao traço de gênero, a autora assume que se trata de um traço valorado e interpretável em $\mathrm{N}$, mas não valorado e não interpretável nos determinantes e adjetivos, que recebem o traço de gênero via concordância com o nome.

Quando se fala, no entanto, da interpretabilidade do traço de gênero, é importante destacar a distinção feita em Corbett (1991) entre sistemas de atribuição de gênero que são semânticos, ou seja, em que o gênero do nome costuma refletir uma distinção biológica, e sistemas puramente formais, em que o gênero depende mais de propriedades de natureza morfossintática do que semântica. A partir dessa distinção entre gênero natural e gênero gramatical, Kramer (2015) revisita a noção de interpretabilidade dos traços de gênero, a partir do sistema da língua amárica, uma língua semítica do tronco das línguas afro-asiáticas. Mais especificamente, a autora propõe que o gênero natural é um traço interpretável no núcleo categorizador $n$, enquanto o gênero arbitrário, por sua vez, é tratado como uma versão não interpretável do mesmo traço no núcleo $n$. Nesse sentido, há uma distinção importante entre valoração e interpretabilidade, diferentemente do que previsto pelo sistema de Chomsky $(2000,2001)$.

7 "Há, presumivelmente, uma relação de concordância similar, porém distinta, Concord, envolvendo apenas merge" (tradução nossa). 


\section{GÊNERO NA PERSPECTIVA DA PSICOLINGUíSTICA: O PROCESSAMENTO ADULTO}

De acordo com Domínguez, Cuetos e Seguíi (2000), questões de processamento envolvendo informações de gênero têm recebido menos atenção na literatura psicolinguística do que questões envolvendo número. Os autores atribuem essa diferença, pelo menos em parte, ao fato de que a grande maioria dos estudos da área tem sido conduzida com base em dados do inglês, uma língua que não apresenta sufixos de gênero e codifica distinções de gênero biológico por meio de entradas lexicais separadas. Na literatura disponivel, as discussões sobre a informação de gênero no âmbito de estudos sobre o processamento adulto recobrem diversos aspectos que vão desde a representação e armazenamento de formas flexionadas no léxico mental - entradas únicas versus unidades decomponíveis em átomos menores - até a computação de relações de concordância no nivel sentencial, passando pela relevância da terminação das palavras no processo de identificação do gênero dos nomes.

No que tange ao processamento de palavras isoladas, Domínguez, Cuetos e Segui $(1999,2000)$ investigam o papel da frequência na determinação do gênero de nomes flexionados. É estabelecida uma distinção entre frequência superficial dos itens e a frequência acumulada de uma determinada raiz, considerando ainda o item dominante de um dado par (masculino ou feminino). A partir de dados do espanhol, os autores comparam os tempos de reação frente a itens como viudo/viuda "viúvo/viúva" (em que viuda é o item dominante do par) e perro/perra "cachorro/cachorra" (em que a forma masculina é a dominante). Os resultados obtidos sugerem diferenças em função da frequência cumulativa dos itens e em função da forma dominante (feminina ou masculina). Os autores consideram que os achados reportados se mostram mais compativeis com modelos mistos da computação da estrutura e do acesso da representação lexical do que com modelos de decomposição total dos itens (full parsing) ou com modelos que pressupõem itens listados como entradas separadas (full listing). Modelos mistos (ou duais) preveem uma distinção entre palavras de alta e baixa frequência: itens de alta frequência seriam acessados de forma direta (sem decomposição), enquanto palavras de baixa frequência seriam acessadas por meio das suas raízes.

Corrêa, Almeida e Porto (2004), por sua vez, questionam as conclusões apresentadas por Domínguez, Cuetos e Segui $(1999,2000)$ com base em resultados de um estudo experimental conduzido no PB. Um conjunto de quatro experimentos de decisão lexical é reportado, no qual gênero gramatical, frequência dominante e categoria gramatical ( $\mathrm{N}$ versus Adj) foram manipulados e a frequência cumulativa das raizes foi controlada. De acordo com os autores, os resultados obtidos não se mostram compativeis com a ideia de que palavras flexionadas em gênero sejam representadas como formas independentes no léxico mental. Pelo contrário, os dados reportados sugerem que nomes e adjetivos (ou suas raizes correspondentes) seriam representados no léxico como formas não marcadas previamente para gênero. Vale destacar que esse tipo de discussão se relaciona de maneira bastante interessante às discussões feitas no âmbito das teorias formalistas a respeito do lugar da informação de gênero.

De acordo com Taft e Meunier (1998), a relação entre a terminação dos nomes e o gênero gramatical de um ponto de vista psicológico foi explorada pela 
primeira vez no trabalho de Tucker et al. (1968). Nesse estudo pioneiro, foram apresentadas pseudopalavras com diversos tipos de terminações para falantes nativos de francês. A tarefa dos participantes consistia em determinar qual gênero correspondia a cada um desses itens. Os resultados indicaram que o gênero atribuído foi compatível à proporção na qual cada uma das terminações investigadas de fato se associa ao gênero masculino ou feminino nessa lingua (TUCKER et al., 1968 apud TAFT; MEUNIER, 1998). Em um segundo estudo, Tucker, Lambert e Rigault (1977 apud TAFT; MEUNIER, 1998) propõem que falantes nativos de francês são capazes de extrair um conjunto de regras por meio das quais as terminações das palavras são associadas a um determinado gênero gramatical.

Ainda no que tange à manifestação do gênero no francês, Taft e Meunier (1998) apontam que nessa língua a relação entre a terminação dos nomes e o gênero gramatical pode ser menos transparente do que, por exemplo, no espanhol, em que a maior parte dos nomes terminados em -o são masculinos e os terminados em $-a$, femininos. Tal discriminação seria menos evidente no francês, apresentando uma aparente maior arbitrariedade. Os autores destacam, no entanto, que certas terminações no francês seriam mais "altamente preditivas" com relação à informação de gênero do que outras. Por exemplo, 98\% dos nomes terminados por -ie são femininos - vie, folie, enquanto 99\% dos nomes terminados por - $t$ são masculinos - tricot, incident. Terminações como -le seriam, por sua vez, menos preditivas, já que correspondem ao gênero masculino apenas em $70 \%$ das ocorrências. Outro ponto relevante no caso do francês está relacionado, de acordo com os autores, com as diferenças entre as formas ortográficas e fonológicas de uma determinada palavra: certas palavras homófonas apresentam formas ortográficas distintas, isto é, a terminação escrita é mais informativa com relação ao gênero do que a terminação fonética. Taft e Meunier (1998) investigam, a partir de três experimentos psicolinguísticos e de uma abordagem de modelagem de redes neurais, em que medida a regularidade e a frequência dos itens influenciam a determinação do gênero dos nomes. Foram considerados itens "irregulares" aqueles que contradizem o esperado com base em sua terminação (Ex. squelette "esqueleto", que é masculino, embora apenas 1\% dos nomes terminados em -ette seja masculino em francês). Em outras palavras, os itens irregulares são aqueles que apresentam "terminações altamente não usuais para seu gênero" (TAFT; MEUNIER, 1998, p. 28). A regularidade/irregularidade da relação entre terminação e gênero foi avaliada em conjunto com a frequência de ocorrência dos itens testados (nomes de alta e baixa frequência de uso). Os resultados obtidos sugerem que a informação relevante para a identificação do gênero dos nomes em francês parece ser extraída de mais de uma fonte, sendo a terminação das palavras apenas uma das possibilidades. Quando outras fontes se encontravam disponíveis, por exemplo, o gênero marcado no artigo, a terminação do nome se mostrou uma pista menos preditiva.

Visando a analisar experimentalmente a generalização parcial entre terminação dos nomes e gênero, comum em diversas línguas românicas, e a obter evidências que possam contribuir para a discussão da natureza da vogal final em Ns, Armelin, Marcilese e Name (2017) investigaram a consciência morfológica dos falantes sobre a vogal final -o como marca de gênero em nomes animados do português brasileiro (PB). Foi elaborado um experimento de leitura automonito- 
rada por meio de uma tarefa de labirinto $\left(\right.$ maze task $\left.{ }^{8}\right)$ contendo pseudonomes animados construídos a partir de padrões de pareamento de gênero legítimos (gramaticais) e ilegitimos (lacuna paradigmática) no PB. Os seguintes pareamentos foram investigados:

- Pareamento biunívoco: - $\mathrm{a} \Rightarrow$-o versus $-\mathrm{o} \Rightarrow$-a

Como em: menina $\rightarrow$ menino / aluno $\rightarrow$ aluna

Exemplo de pseudonomes utilizados: a fupa $\rightarrow$ o fupo / o dabo $\rightarrow$ a daba

- Pareamento variável gramatical: -e $\Rightarrow$-a versus $\varnothing \Rightarrow$-a

Como em: mestre $\rightarrow$ mestra / peru $\rightarrow$ perua

Exemplo de pseudonomes utilizados: o lude $\rightarrow$ a luda / o puzal $\rightarrow$ a puzala

- Pareamento variável agramatical (lacuna paradigmática): -e $\Rightarrow$-o versus $\varnothing$ $\Rightarrow$-o

Como em: estudante $\rightarrow$ *estudanto / aprendiz $\rightarrow$ *aprendizo

Exemplo de pseudonomes utilizados: a dufe $\rightarrow$ o dufo / a nebal $\rightarrow$ o nebalo

Os resultados obtidos tanto para os tempos de leitura/escolha quanto para as escolhas em si sugerem que, em termos de consciência morfológica, as vogais finais - $a$ e -o são tratadas de forma equivalente no tipo de tarefa experimental empregada. Em outras palavras, os achados experimentais parecem indicar que, seja qual for a natureza exata das vogais finais - $a$ e -o em nomes animados, ambos os elementos parecem fazer parte de uma mesma categoria. Os resultados sugerem ainda que os falantes aceitam pareamentos não disponiveis na língua, mas que seguem padrões virtualmente possiveis, o que reforça a ideia de uma categorização uniforme das vogais finais em nomes animados. Esse tipo de discussão pode abrir diálogos interessantes com as questões relativas à relação entre gênero e a vogal final dos nomes, já delineadas anteriormente neste artigo sob um viés formalista.

Por fim, no que tange ao processamento de relações de concordância - isto é, fora do âmbito de palavras isoladas - Barber e Carreiras (2005) investigaram o processamento das representações de gênero e número durante a leitura de estímulos em espanhol, formados por nomes invariantes para gênero (i. e., contendo apenas gênero gramatical, mas não semântico). Os autores reportam resultados da atividade eletrofisiológica do cérebro dos participantes obtidos a partir da técnica de potenciais relacionados a eventos (ERP, event-related potentials) que seriam compativeis com a ideia de que, enquanto gênero corresponderia a um traço da representação lexical, número teria a natureza de um traço morfológico que se combina com uma raiz. Ao contrastar a atividade cerebral dos participantes frente a incongruências de gênero e de número, os padrões observados foram significativamente distintos em função das condições que incluiam sintagmas formados por: 1 . D + N congruentes em gênero e número, incongruentes apenas para gênero ou apenas para número (Ex. el piano "o piano" / *la piano "a piano" / *los piano "os piano"); ou 2. N + ADJ (Ex. faro alto "farol alto" / *farol alta "farol alta" / *farol altos "farol altos").

8 A maze task consiste em uma alternativa ao paradigma padrão de leitura automonitorada. Nesse tipo de tarefa, o participante percorre o "labirinto", realizando a leitura a partir da escolha de palavras ou segmentos que são apresentados em pares e precisam ser integrados ao contexto prévio. O tempo gasto para realizar a leitura/escolha de cada segmento e o registro da opção escolhida são gravados para posterior análise. 


\section{GÊNERo NA PERSPECTIVA DA PSICOLINGUísticA: AgUISIÇÃo DA LINGUAGEM}

Como vimos na introdução deste artigo, a presença de sistemas de gênero gramatical é uma constante em boa parte das línguas naturais já descritas. A ocorrência de correlatos morfológicos com um grau não desprezível de sistematicidade e de manifestações de relações de concordância envolvendo informação de gênero também se mostra particularmente relevante. Diante desse quadro, uma questão crucial que se coloca na pesquisa em aquisição da linguagem é como, ao adquirir o léxico da língua, a criança identifica o valor do traço de gênero dos nomes: a partir de estratégias guiadas pelo léxico (pelo mapeamento valor do traço-correlato morfofonológico) e/ou da operação de concordância no $\mathrm{DP}$ (entre D e/ou ADJ e N). O primeiro tipo de estratégia seria eficiente para os casos de padrões mais consistentes, mas dependeria da ampliação do vocabulário para a criança reconhecer e abstrair tais padrões, de modo a generalizá-los em novas aquisições; padrões alternativos, menos consistentes, teriam de ser identificados por meio de concordância. Os estudos selecionados e apresentados a seguir, conduzidos com crianças adquirindo francês, espanhol ou PB, buscam discutir esses pontos.

O estudo de Karmiloff-Smith (1979), com crianças francesas de 3 a 11 anos, é provavelmente o primeiro trabalho de cunho experimental sobre aquisição de gênero. A autora usou pseudonomes para investigar que pistas seriam usadas para a identificação do gênero do nome. Era apresentada uma imagem (de um ser animado ou inanimado) acompanhada de um enunciado (Aqui tem a imagem de...) e, ao apresentar uma segunda imagem, igual à primeira, era perguntado à criança: E aqui, o que tem?. Os fatores investigados foram: 1. informação de gênero em D (masculino/feminino); 2. terminação de N (terminações mais frequentes em nomes masculinos e femininos); e 3. informação semântica (imagem de ser animado ou inanimado), em condições apresentando congruência de gênero (todas as pistas de um mesmo gênero) ou incongruência (pistas conflitantes). Os resultados obtidos sugerem que, independentemente da faixa etária, as crianças privilegiaram informações linguísticas - gênero manifesto em $\mathrm{D}$ e terminação de $\mathrm{N}$, e essas duas pistas apresentadas juntas elevaram a taxa de acertos para a quase totalidade $(95,9 \%)$. Não houve uso significativo da pista semântica. Diante de incongruência de informação entre D e terminação de $\mathrm{N}$, as crianças acima de seis anos privilegiaram a pista de D, mas as respostas das crianças menores não indicaram preferência por uma ou outra pista.

É importante notar que o estudo de Karmiloff-Smith (1979), que fez uso de uma tarefa off-line, de produção eliciada, foi realizado com crianças de uma ampla faixa de idade e que, mesmo as mais novas, já produziam enunciados simples. Seus resultados permitem defender que, aos três anos, crianças adquirindo o francês já conhecem o sistema de gênero da língua - os elementos que sinalizam gênero e seus valores -, mas não podem ser generalizados para o uso dessas informações no processamento on-line de enunciados, nem assumir que somente a partir dessa idade as crianças estariam aptas a usá-las. Trabalhos mais recentes se voltaram para faixas etárias mais baixas e usaram técnicas experimentais on-line. Van Heugten e Christophe (2015) observaram que crianças francesas de 18 meses reconhecem o gênero de palavras frequentes e estranham quando há incongruência entre o gênero do determinante que acompanha o nome conhecido (le vs. *la pain "o/*a pão", la vs. *le main "a/*o mão"). 
Usando a técnica de Olhar Preferencial (Split-Screen Preferential Looking Procedure), Van Heugten e Shi (2009) verificaram que crianças de 21 a 24 meses, adquirindo o francês canadense, são capazes de prever a palavra (associada a uma imagem conhecida) subsequente ao determinante em função do gênero deste. Diante de imagens de objetos cujos nomes começam pela mesma sequência sonora (por exemplo, [ba]nane - "banana", [ba]teau - "barco", [ba]llon - "bola"), as crianças dirigiram seu olhar à imagem-alvo mais rapidamente na condição informativa, i.e., quando o gênero do determinante era compativel apenas com um dos dois nomes/imagens apresentados (la banane, para as imagens de banane (fem.) e de bateau (masc.)), do que na condição não informativa, em que as duas imagens remetiam a nomes de mesmo gênero (batteau e ballon).

No espanhol, Pérez-Pereira (1991) realizou estudo semelhante ao de Karmiloff-Smith (1979), investigando o uso de diversas pistas, linguísticas e extralinguísticas, por crianças de 4 a 11 anos em uma tarefa de identificação do gênero de nomes inventados. Era apresentado um desenho de um objeto ou de um animal imaginários, acompanhado de um enunciado (Aqui tem...). Em seguida, era apresentado o mesmo desenho em outra cor e era pedido à criança que respondesse à pergunta: $O$ que tem aqui?. Vinte e dois pseudonomes foram criados e foram manipuladas pistas linguísticas: 1. o gênero expresso em D (manifesto masc., fem.; ausente - numeral dos, não marcado em gênero); 2. a terminação de N (informativa - masc. -o, fem. -a; não informativa - diferente dessas), e extralinguística, relativa ao referente; 3. gênero biológico ou não (desenho de animal ou objeto). O pesquisador testou, ainda, a sobreposição de pistas, com enunciados apresentando apenas um elemento marcado ( $\mathrm{D}$ ou $\mathrm{N}$ ou desenho), dois (D e N, D e desenho, $\mathrm{N}$ e desenho) ou os três elementos marcados, sendo as pistas redundantes (todas de um mesmo gênero) ou conflitantes (uma pista ou duas pistas diferindo das demais). Em conjunto, os resultados apontaram que a combinação das pistas aumentou a taxa de acerto para ambos os gêneros em todas as idades, e que informações de natureza linguística (gênero de D e vogal final de N) foram mais usadas do que a extralinguística (gênero biológico). Ainda, houve maior taxa de acertos nas condições com pistas de gênero masculino, o que, segundo o autor, seria compativel com a ideia de o masculino ser a forma não marcada. Diferenças em relação à idade foram observadas apenas nas condições que apresentavam conflito entre as pistas, sinalizando uma preferência das crianças mais velhas pela pista morfológica (gênero de D), enquanto as mais novas se guiaram mais pela terminação de $\mathrm{N}$.

Lew-Williams e Fernald (2007) aplicaram um experimento semelhante ao de Van Heugten e Shi (2009) a crianças espanholas de 34 a 42 meses $(2,10$ a 3,6 anos), usando o procedimento de rastreamento ocular, que permite aferir mais precisamente o momento em que o/a participante começa a direcionar o olhar para uma dada imagem e a latência de fixação. Os resultados indicaram uma orientação mais rápida para a imagem-alvo na condição informativa, e esse comportamento foi mais consistente em crianças com pontuação mais alta em testes de vocabulário e de desenvolvimento linguístico, independentemente da idade. Para as autoras, esses resultados sugerem uma conexão entre desenvolvimento linguístico e eficiência de processamento.

Ainda no espanhol, Arias-Trejo e Alva (2013) buscaram investigar o uso de morfologia flexional de gênero no adjetivo na atribuição de gênero a pseudonomes por crianças mexicanas de 30 meses. Numa primeira etapa, a criança era 
apresentada a uma imagem de objeto inanimado, acompanhada de enunciado apenas com adjetivo marcado em gênero (Mira! Es rojo); em seguida, outra imagem era apresentada, com o mesmo tipo de enunciado (Ve! Es amarilla). No teste, as duas imagens eram apresentadas juntas e o enunciado apresentava um pseudonome (Mira/Ve um pileco/una betusa). O objetivo era avaliar se a criança seria capaz de associar a informação de gênero apresentada no adjetivo com a informação de gênero veiculada pelo determinante, realizando a concordância N-Adj (a distância) e D-N. Efetivamente, os resultados foram compativeis com o esperado, com maior fixação do olhar na imagem-alvo pelas crianças. No entanto, no espanhol, assim como no português, nomes terminados em -o tendem a ser masculinos e terminados em - $a$ tendem a ser femininos, de modo que não é claro se as crianças se guiaram pela morfologia flexional de gênero no adjetivo ou pela terminação do pseudonome (ou, ainda, por ambas).

Alguns estudos realizados no PB abordaram essa questão, buscando investigar o papel da terminação de $\mathrm{N}$ e da morfologia flexional em D e ADJ, separadamente, no reconhecimento do gênero em nomes conhecidos e na atribuição de gênero em novos nomes por crianças brasileiras. Name (2002; CORREAA; NAME, 2003) verificou que, numa tarefa de seleção de imagem, crianças de 23 meses (média de idade) escolhem facilmente a imagem-alvo relacionada a um nome conhecido da criança associado a determinante congruente em gênero, e que a incongruência entre o gênero de $\mathrm{D}$ e de $\mathrm{N}$ afeta significativamente o desempenho das crianças na tarefa. Esses resultados são compativeis com os achados de Van Heugten e Shi (2009) com crianças da mesma faixa etária adquirindo o francês canadense.

No que se refere à informação morfológica veiculada em $\mathrm{D}$, decorrente da concordância entre D e N, Corrêa e Name (2003) testaram crianças com idade abaixo de três anos (média de 31 meses) e acima de três anos (média de 54,2 meses) em uma tarefa de produção eliciada. Uma história era contada à criança com o auxílio de imagens, em que apareciam objetos inventados de diferentes cores, apresentados por pseudonomes: Isso é um/uma...; aqui também é um/ uma...; os/as... estão... um/uma... caiu, qual... caiu?. Os fatores investigados foram o gênero manifesto em D (masc., fem.) e a terminação de $\mathrm{N}$ (-a, -o, -e), que, cruzados, geraram condições com informação redundante (D e terminação de $\mathrm{N}$ sinalizando mesmo gênero: o puco, a depa), informação conflitante (gêneros distintos para D e terminação de N: o depa, a puco) e neutra (D masc. ou fem. associado a N-e: o/ a mipe). Todas as crianças tiveram alta taxa de acertos na condição de informação redundante, próxima de $100 \%$, e na condição neutra, próxima de $90 \%$. Na condição conflitante, as crianças menores de três anos mantiveram a taxa de acertos alta (89\%), ao passo que as crianças mais velhas acertaram apenas 62,3\% dos ensaios. Esses resultados sugerem que as crianças mais novas privilegiaram a informação do determinante; as crianças acima de três anos também a usaram, mas foram influenciadas ainda pela terminação de N. Diferentemente, os resultados de Karmiloff-Smith (1979) e de Pérez-Pereira (1991), para o francês e o espanhol, respectivamente, apontaram para o uso preferencial da informação em D por crianças a partir de seis anos nas condições de conflito, com as crianças mais novas se baseando principalmente na pista da terminação de $\mathrm{N}$.

Bogo (no prelo; BOGO; NAME, 2019) explorou a morfologia flexional de gênero nos adjetivos, para investigar se ela seria uma pista robusta para a criança atri- 
buir gênero a pseudonomes. A autora manipulou a congruência entre terminação de $\mathrm{N}(-\mathrm{o},-\mathrm{a})$ e flexão de gênero em ADJ (masc., fem.), apresentando N e ADJ em concordância em um mesmo enunciado, com informação redundante (mesmo gênero na vogal temática e na flexão) ou conflitante (gêneros diferentes). Vinte e seis crianças de três a cinco anos foram testadas usando-se a tarefa de produção eliciada. Ao longo de uma pequena história, eram apresentados objetos nomeados por pseudonomes acompanhados de adjetivos: beco vermelho, moca branca (condição redundante); depa amarelo, dabo preta (condição não redundante). A análise preliminar dos resultados apontou um efeito principal de terminação de $\mathrm{N}$ nas três faixas etárias, refletindo a produção das crianças, que usaram essa fonte de informação para definir o gênero de $\mathrm{N}$ em suas respostas. Não houve diferença entre masculino e feminino nas respostas das crianças de quatro e cinco anos, mas as crianças de três anos foram sensiveis à morfologia do adjetivo marcado no feminino, conforme apontado pelo efeito de interação entre terminação e flexão de gênero nesse grupo. Mais uma vez, os resultados com crianças adquirindo o PB sugerem que, comparativamente, crianças mais novas (em torno ou abaixo de três anos) são mais sensiveis a pistas morfológicas decorrentes de concordância D-N e N-Adj do que crianças acima dessa idade, ainda que também usem informação da terminação de $\mathrm{N}$ para atribuir gênero a um nome desconhecido.

\section{CONSIDERAÇÕES FINAIS}

Distinções gramaticais baseadas em gênero são amplamente disseminadas entre as linguas naturais. Sistemas de gênero gramatical parecem estar crucialmente vinculados a correlatos morfofonológicos relativamente sistemáticos e regulares e parecem se manifestar em relações de concordância entre $\mathrm{N}$ e outros elementos, fundamentalmente das categorias D e ADJ. Nesse sentido, neste artigo selecionamos três questões centrais para discussão: 1. o lugar da informação de gênero; 2 . a relação entre a informação de gênero e a realização morfofonológica final do nome; e 3. as relações de concordância estabelecidas dentro do sintagma determinante. Com o objetivo de fornecer ao leitor um olhar panorâmico, essas questões foram recuperadas à luz de propostas formalistas no contexto dos estudos linguísticos e de resultados experimentais obtidos no contexto de pesquisas sobre o processamento e a aquisição da linguagem.

No que tange à questão 1 , vimos que, nas teorias formalistas, a ideia de que a informação de gênero corresponde a um traço de natureza formal está bastante difundida na literatura, havendo uma forte tendência a pensar que se trata de uma informação que pertence, inerentemente, a uma das projeções funcionais que compõem o domínio do nome. No contexto de abordagens psicolinguísticas, a discussão sobre o fato de gênero ser uma informação inerente aos nomes - que poderiam, portanto, ser acessados como entradas independentes - ou uma informação associada a uma dada raiz ainda é uma questão em debate. Outras questões em aberto referem-se ao papel de certos fatores relevantes para o processamento, tais como a regularidade dos itens, a frequência e o item dominante de um determinado par delimitado a partir da informação de gênero.

No que diz respeito à questão 2 , há um debate na formalização da natureza da vogal final do nome. No PB, tal questão fica ainda mais saliente quando se 
olha para as realizações -a e -o, ora tratadas como expoente de gênero, ora tratadas como vogais temáticas. No âmbito do processamento adulto, os resultados experimentais de Armelin, Marcilese e Name (2017) parecem apontar para um estatuto unificado dessas duas realizações. Nesse mesmo sentido, do ponto de vista da aquisição, padrões morfofonológicos na terminação de nome se mostram bastante relevantes para a identificação do gênero nos nomes.

Finalmente, a questão 3 explorou formalmente o mecanismo de concordância de gênero, através da exposição do sistema de Agree elaborado em Chomsky (2000, 2001) e estendido ao domínio do DP em abordagens como a de Magalhães (2004). Do ponto de vista do processamento, parece haver uma assimetria entre gênero, que corresponderia a um traço da representação lexical, e número, que teria a natureza de um traço morfológico que se combina com uma raiz. Já na perspectiva da aquisição, destaca-se o alto desempenho de crianças em variadas faixas etárias quando as atividades envolvem congruência de gênero nos elementos do sintagma. Por outro lado, as atividades experimentais em que há algum tipo de incongruência na concordância parecem apontar ora para uma maior relevância da terminação do nome, ora para uma maior relevância da informação do determinante.

Longe de pretender esgotar o assunto, nosso objetivo foi delinear alguns pontos de confluência e mostrar alguns caminhos nos quais uma abordagem baseada no diálogo entre abordagens formais e procedurais, no contexto de teorias linguísticas e psicolinguísticas, parece ser a opção mais fértil para uma melhor compreensão das questões levantadas.

\section{ON THE MORPHOLOGICAL MANIFESTATION OF GENDER: FORMAL AND PSYCHOLINGUISTIC APPROACHES}

Abstract: This paper revisits, in a panoramic way, questions related to the notion of grammatical gender from linguistic and psycholinguistic perspectives. In general terms, three major issues are explored: 1 . the locus of gender information; 2. the relation between gender value and the ending of the noun; and 3. the establishment of an agreement relation between the noun, the adjective, and the determiner. Aspects of each of these questions are explored under a formalist approach, in terms of adult processing and also from the language acquisition perspective.

Keywords: Morphosyntax. Grammatical gender. Formalism. Language processing. Language acquisition.

\section{REFERÊNCIAS}

ACQUAVIVA, P. Roots and lexicality in Distributed Morphology. In: GALANI, A.; REDINGER, D.; YEO, N. (ed.). York essex morphology meeting 5. York: University of York, 2009. p. 1-21.

ALCÂNTARA, C. As classes formais do português brasileiro. Letras de Hoje, Porto Alegre, v. 45, n. 1, p. 5-15, 2010. 
ALEXIADOU, A.; MÜLLER, G. Class features as probes. In: BACHRACH, A.; NEVINS, A. (ed.). Inflectional identity. Oxford: Oxford University Press, 2008. p. 101-155.

ARIAS-TREJO, N.; ALVA, E. A. Early Spanish grammatical gender bootstraping: learning nouns through adjectives. Development Psychology, v. 49, n. 7, p. 13081314, 2013.

ARMELIN, P. R. G. Classifying nominals in Brazilian Portuguese. In: VESELOVSKÁ, L.; JANEBOVÁ, M. (ed.). Complex visible out there: language, use and linguistic structure. Olomouc Modern Languages Series, v. 4, p. 67-82, 2014.

ARMELIN, P. R. G.; MARCILESE, M.; NAME, C. Um estudo experimental sobre a consciência morfológica da vogal final -o como marca de gênero nos nominais do português brasileiro. In: SIMPÓSIO MUNDIAL DE ESTUDOS DA LÍNGUA PORTUGUESA, 6., 2017, Santarém. Anais [...]. Santarém, Portugal, 2017.

BAKER, M. The syntax of agreement and concord. Cambridge: Cambridge University Press, 2008.

BARBER, H.; CARREIRAS, M. Grammatical gender and number agreement in Spanish: an ERP comparison. Journal of Cognitive Neuroscience, v. 17, n. 1, p. 137-153, 2005.

BÉJAR, S.; REZAC, M. Cyclic Agree. Linguistic Inquiry, v. 40, p. 35-73, 2009.

BOGO, O. F. A identificação do sistema de gênero nos sintagmas nominais no $P B$. Dissertação (Mestrado em Linguística) - Universidade Federal de Juiz de Fora. No prelo.

BOGO, O. F.; NAME, C. A identificação do sistema de gênero em sintagmas nominais do PB. In: CONGRESSO ABRALIN 50, 2019, Maceió. Anais [...]. Maceió: Abralin, 2019.

CÂMARA JR., M. Estrutura da lingua portuguesa. Petrópolis: Vozes, 1970.

CHOMSKY, N. The minimalist program. Cambridge: MIT Press, 1995.

CHOMSKY, N. Minimalist inquiries: the framework. In: MARTIN, R.; MICHAELS, D.; URIAGEREKA, J. (ed.). Step by step: essays on minimalist syntax in honor of Howard Lasnik. Cambridge: MIT Press, 2000. p. 89-155.

CHOMSKY, N. Derivation by phase. In: KENSTOWICZ, M. (ed.). Ken Hale: a life in language. Cambridge: MIT Press, 2001. p. 1-52.

COMRIE, B. Grammatical gender systems: a linguist's assessment. Journal of Psycholinguistic Research, v. 28, n. 5, p. 457-466, 1999.

CORBETT, G. Gender. Cambridge: Cambridge University Press, 1991.

CORBETT, G. G. Number of genders. In: DRYER, M. S.; HASPELMATH, M. (ed.). The World Atlas of Language Structures Online. Leipzig: Max Planck Institute for Evolutionary Anthropology, 2013. Disponivel em: https://wals.info/feature. Acesso em: 11 nov. 2019.

CORREA, L. M. S.; ALMEIDA, D. A.; PORTO, R. P. On the representation of Portuguese gender-inflected words in the mental lexicon. Brain and Language, v. 90, p. 63-73, Jan. 2004.

CORREAA, L. M. S.; NAME, C. The processing of determiner: noun agreement and the identification of the gender of nouns in early acquisition of Portuguese. Journal of Portuguese Linguistics, v. 2, n. 1, p. 19-43, 2003. 
DOMínGUEZ, A.; CUETOS, F.; SEGUI, J. Morphological processing in word recognition: a review with particular reference to Spanish data. Psicológica, v. 21, p. 375-401, 2000.

DOMÍNGUEZ, A.; CUETOS, F.; SEGUI, J. The processing of grammatical gender and number in Spanish. Journal of Psycholinguistic Research, v. 28, n. 5, p. 485-498, 1999.

EMBICK, D. The morpheme: a theoretical introduction. Boston: De Gruyter Mouton, 2015.

HALLE, M.; MARANTZ, A. Distributed morphology and the pieces of inflection. In: HALE, K.; KEYSER, S. J. (ed.). The view from Building 20. Cambridge: MIT Press, 1993. p. 111-176.

KARMILOFF-SMITH, A. A functional approach to child language: a study of determiners and reference. Cambridge: Cambridge University Press, 1979.

KIHM, A. Noun class, gender and the lexicon-syntax-morphology interfaces: a comparative study of Niger-Congo and Romance languages. In: CINQUE, G.; KAYNE, R. S. (ed.). The Oxford Handbook of Comparative Syntax. Oxford: Oxford University Press, 2005. p. 459-512.

KRAMER, R. The morphosyntax of gender. Oxford: Oxford University Press, 2015. LEW-WILLIAMS, C.; FERNALD, A. Young children learning Spanish make rapid use of grammatical gender in spoken word recognition. Psychological Science, n. 18, p. 193-198, 2007.

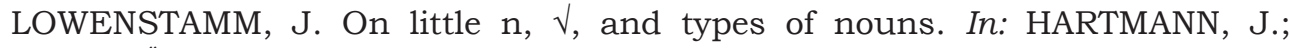
HEGEDÜS, V.; RIEMSDIJK, H. (ed.). Sounds of silence: empty elements in syntax and phonology. Amsterdam: Elsevier, 2008. p. 105-144.

MAGALHÃES, T. M. V. A valoração de traços de concordância dentro do DP. Delta, São Paulo, v. 20, n. 1, p. 149-170, 2004.

MATASOVIĆ, R. Gender in Indo-European. Heidelberg: Winter, 2004.

NAME, C. Habilidades perceptuais e linguisticas no processo de aquisição do sistema de gênero no português. 2002. Tese (Doutorado) - Pontificia Universidade Católica do Rio de Janeiro, Rio de Janeiro, 2002.

OLTRA-MASSUET, I. On the notion of theme vowel: a new approach to Catalan verbal Morphology. 1999. Tese (Doutorado) - Massachusetts Institute of Technology, Cambridge, 1999.

PÉREZ-PEREIRA, M. The acquisition of gender: what Spanish children tell us. Journal of Child Language, v. 18, n. 3, p. 571-590, 1991.

PICALLO, M. C. Nominals and nominalization in Catalan. Probus, v. 3, p. 279316, 1991.

PREMINGER, O. Agreement and its failures. Cambridge: MIT Press, 2014.

RITTER, E. Where's gender? Linguistic Inquiry, v. 24, p. 795-803, 1993.

TAFT, M.; MEUNIER, F. Lexical representation of gender: a quasiregular domain. Journal of Psycholinguistic Research, v. 27, n. 1, p. 23-45, 1998.VAN BERKUM, J. J. A. Syntactic Processes in speech production: the retrieval of grammatical gender. Cognition, v. 64, n. 2, p. 115-152, Aug. 1997. 
DOSSIÊ

VAN HEUGTEN, M.; CHRISTOPHE, A. Infants' acquisition of grammatical gender dependencies. Infancy, v. 20, n. 6, p. 675-683, 2015.

VAN HEUGTEN, M.; SHI, R. French-learning toddlers use gender information on determiners during word recognition. Development Science, v. 12, n. 3, p. 419425, Apr. 2009. 